

Jurnal Akuntansi AKTIVA, Vol 1, No 1, April 2020

\title{
EFEK PERISTIWA POLITIK TERHADAP ABNORMAL RETURN DAN \\ TRADING VOLUME ACTIVITY PADASAHAM LQ-45 (EVENT STUDY \\ PADA
}

VONIS YANG DIBERIKAN BASUKI THAJAJA PURNAMA)

\author{
${ }^{1}$ Peti Mei Andari, ${ }^{2}$, Nedi Hendri, ${ }^{3}$ Jawoto Nusantoro \\ Universitas Muhammadiyah Metro, J1. Ki Hajar Dewantara, 34111, Lampung, Indonesia \\ Universitas Muhammadiyah Metro, J1. Ki Hajar Dewantara, 34111, Lampung, Indonesia \\ E-mail: ptymei8@gmail.com nedi_hendri@yahoo.com.pakjawoto@yahoo.co.id
}

\begin{abstract}
This study aims to verify whether the percentage of stock offerings, company age, and market timing affect the underpricing of companies that make Initial Public Offering (IPO) during 2014-2017. This research is a type of quantitative research and the data analysis method used is multiple linear regression analysis. The sampling technique used in this study was a purposive sampling technique with certain criteria, so that 76 sample companies were obtained.

Based on the results of data analysis that has been done, it is found that the percentage variable share offering has a significant effect on the level of underpricing, while the age variable of the company has no significant effect on the level of underpricing. In addition, it was found that the market timing variable had a significant effect on the level of underpricing and simultaneously the percentage of shares offering, company age, and market timing had a significant effect on the level of underpricing of companies that conducted Initial Public Offering (IPO) on the Indonesia Stock Exchange.
\end{abstract}

Keywords: Underpricing, Initial Public Offering, Percentage of Stock Offerings, Company Age, Market Timing

\section{ABSTRAK}

Penelitian ini bertujuan untuk memverifikasi apakah persentase penawaran saham, usia perusahaan, dan waktu pasar mempengaruhi underpricing perusahaan yang melakukan Penawaran Umum Perdana (IPO) selama 2014-2017. Penelitian ini merupakan jenis penelitian kuantitatif dan metode analisis data yang digunakan adalah analisis regresi linier berganda. Teknik pengambilan sampel yang digunakan dalam penelitian ini adalah teknik purposive sampling dengan kriteria tertentu, sehingga diperoleh 76 perusahaan sampel. 
Berdasarkan hasil analisis data yang telah dilakukan, didapatkan bahwa persentase penawaran saham variabel berpengaruh signifikan terhadap tingkat underpricing, sedangkan variabel umur perusahaan tidak berpengaruh signifikan terhadap tingkat underpricing. Selain itu, ditemukan bahwa variabel market timing berpengaruh signifikan terhadap tingkat underpricing dan secara bersamaan persentase penawaran saham, usia perusahaan, dan market timing berpengaruh signifikan terhadap tingkat underpricing perusahaan yang melakukan Penawaran Umum Perdana. (IPO) di Bursa Efek Indonesia.

Kata kunci: Underpricing, Penawaran Umum Perdana, Persentase Penawaran Saham, Usia Perusahaan, Waktu Pasar

\section{PENDAHULUAN}

\section{Latar Belakang Penelitian}

Dalam instrumen ekonomi, pasar modal tidak lepas dari pengaruh lingkungan ekonomi maupun lingkungan non ekonomi. Pengaruh lingkungan ekonomi salah satunya dipengaruhi oleh peristiwaperistiwa politik seperti adanya Pemilihan Presiden (Pilpres), Pemilihan Legislative, Pergantian Pemerintahan, Pengumuman Kabinet Menteri, Kerusuhan Politik, Peperangan dan Peristiwa lainnya sangat mempengaruhi harga dan volume perdagangan dibursa efek karena peristiwa-peristiwa politik berkaitan erat dengan kestabilan perekonomiaan negara. Selain itu peristiwa politik juga menyebabkan tingkat kepercayaan yang negatif dari para investor sehingga adanya peristiwa politik yang mengancam kestabilan negara cenderung mendapat respon negatif dari pelaku pasar (Lamasigi, 2012).

Kasus yang akan difokuskan pada penelitian ini adalah kasus Ahok pasca putusan sidang atas penodaan agama.Pasca vonis tersebut gerak indeks harga saham gabungan (IHSG) variatif dengan kecenderungan melemah menjelang penutupan sesi kedua perdagangan saham pada selasa, 9 Mei 2017 jam 16:00 WIB. Indeks harga saham gabungan (IHSG) merespon negatif putusan sidang Basuki Tjahaja Purnama alias Ahok dalam kasus penodaan agama. IHSG sesi jam 12:00 WIB ditutup melemah 3,89 poin atau 0,07\%di level 5.703 (marketbisnis.com, 09/05/2017). Padahal sebelum putusan keluar, IHSG menyentuh rekor tertingginya di level 5.730.

\section{Rumusan Masalah}

1. Apakah terdapat perbedaan Abnormal Return saham sebelum dan sesudah terjadinya Vonis Ahok?

2. Apakah terdapat perbedaan Trading Volume Activity sebelum dan sesusah terjadinya Vonis Ahok? 


\section{KAJIAN TEORITIK}

\section{Teori Pasar Efisien}

Menurut Tandeliln (2010) pasar modal efisien adalah pasar modal yang harga semua sekuritas yang diperdagangkan telah mencerminkan semua informasi yang tersedia. Informasi yang tersedia dapat meliputi semua informasi di masa lalu, informasi saat ini, serta informasi yang bersifat sebagai pendapat atau opini rasional yang beredar yang bisa mempengaruhi perubahan harga. Informasi adalah kunci untuk menentukan harga saham sehingga informasi merupakan masalah utama dalam konsep efisiensi pasar.

\section{Event Study}

Studi peristiwa merupakan studi yang mempelajari reaksi pasar terhadap suatu peristiwa yang informasinya dipublikasikan sebagai suatu pengumuman. Event study digunakan menguji kandingan informasi dari suatu pengumuman dan dapat juga digunakan untuk menguji efisiensi pasar bentuk setengah kuat (Jogiyanto, 2008).

\section{Abnormal Return}

Abnormal return menurut Jogiyanto (2003) adalah selisis antara tingkat keuntungan sebenernya (acrual return) dengan tingkat keuntungan yang diharapkan (expected return). Abnormal return merupakan kelebihan dari return yang sesungguhnya terjadi terhadap return normal. Return normal merupakan return yang diharapkan oleh investor dengan mempertimbangkan tingkat resiko nya.

\section{Trading Volume Activity}

Volume perdagangan saham merupakan rasio antara jumlah lembar saham yang diperdagangkan pada waktu tertentu terhadap jumlah saham yang beredar pada waktu tertentu (Husman dalam Pramana 2012). Volume perdagangan merupakan salah satu indikator yang digunakan untuk melihat reaksi pasar terhadap peristiwa atau informasi yang berkaitan dengan suatu saham.

\section{Penelitian Terdahulu}

\begin{tabular}{|c|c|c|c|c|}
\hline No & Peneliti & Judul & $\begin{array}{c}\text { Variabel dan metode } \\
\text { analisis }\end{array}$ & Hasil \\
\hline 1 & $\begin{array}{l}\text { Dewi dan } \\
\text { Putra } \\
(2013)\end{array}$ & $\begin{array}{l}\text { Pengaruh } \\
\text { pengumuman } \\
\text { right issue } \\
\text { pada abnormal } \\
\text { return dan } \\
\text { trading volume } \\
\text { activity }\end{array}$ & $\begin{array}{l}\text { Abnormal return dan } \\
\text { trading volume activity } \\
\text { Jenis Penelitian: } \\
\text { Event study }\end{array}$ & $\begin{array}{l}\text { Hasilnya tidak } \\
\text { terdapat perbedaan } \\
\text { abnormal return dan } \\
\text { trading volume } \\
\text { activity sebelum dan } \\
\text { sesudah peristiwa }\end{array}$ \\
\hline 2 & $\begin{array}{l}\text { Luhur } \\
(2010)\end{array}$ & $\begin{array}{l}\text { Reaksi pasar } \\
\text { modal } \\
\text { Indonesia }\end{array}$ & $\begin{array}{l}\text { Abnormal return dan } \\
\text { trading volume activity }\end{array}$ & $\begin{array}{l}\text { Tidak terdapat } \\
\text { perbedaan abnormal } \\
\text { return dan trading }\end{array}$ \\
\hline
\end{tabular}




\begin{tabular}{|c|c|c|c|c|}
\hline & & $\begin{array}{l}\text { seputar } \\
\text { pemilihan } \\
\text { umum } 8 \text { Juli } \\
2009 \quad \text { pada } \\
\text { saham LQ-45 }\end{array}$ & $\begin{array}{l}\text { Jenis Penelitian: } \\
\text { Event study }\end{array}$ & $\begin{array}{l}\text { volume activity } \\
\text { sebelum dan sesudah } \\
\text { peristiwa }\end{array}$ \\
\hline 3 & $\begin{array}{l}\text { Lia dan } \\
\text { Endi } \\
(2012)\end{array}$ & $\begin{array}{l}\text { Reaksi pasar } \\
\text { modal } \\
\text { Indonesia } \\
\text { terhadap } \\
\text { pergantian } \\
\text { Menteri } \\
\text { Keuangan } \\
\text { (Event study } \\
\text { saham yang } \\
\text { terdaftar di } \\
\text { BEI) }\end{array}$ & $\begin{array}{l}\text { Abnormal Return, } \\
\text { Trading Volume } \\
\text { Activity dan Security } \\
\text { Return Variability }\end{array}$ & $\begin{array}{l}\text { Hasilnya terdapat } \\
\text { perbedaan yang } \\
\text { signifikan abnormal } \\
\text { return dan trading } \\
\text { volume activity } \\
\text { sebelum dan sesudah } \\
\text { namun tidak terdapat } \\
\text { perbedaan terhadap } \\
\text { Security Return } \\
\text { Valiabilitysebelum } \\
\text { dan } \\
\text { sesudahkemunduran } \\
\text { Menteri Keuangan }\end{array}$ \\
\hline 4 & $\begin{array}{l}\text { Liwe, } \\
\text { Tommy } \\
\text { dan Marais } \\
(2018)\end{array}$ & $\begin{array}{l}\text { Reaksi } \\
\text { investor dalam } \\
\text { pasar modal } \\
\text { atas peristiwa } \\
\text { menguatnya } \\
\text { kurs dolar } \\
\text { Amerika } \\
\text { Serikat } \\
\text { terhadap nilai } \\
\text { tukar kurs } \\
\text { Rupiah pada } \\
26 \quad \text { Agustus } \\
2015\end{array}$ & $\begin{array}{l}\text { Abnormal return dan } \\
\text { trading volume activity }\end{array}$ & $\begin{array}{lr}\text { Hasilnya } & \text { terdapat } \\
\text { perbedaan } & \text { yang } \\
\text { signifikan abnormal } & \text { return dan trading } \\
\text { volume } & \text { activity } \\
\text { sebelum dan sesudah } \\
\text { menguatnya kurs } \\
\text { dolar Amerika } \\
\text { Serikat terhadap nilai } \\
\text { tukar Rupiah pada } 26 \\
\text { Agustus 2015 }\end{array}$ \\
\hline
\end{tabular}

Sumber: Dirangkum dari berbagai jurnal.

\section{Abnormal Return Terhadap Vonis Basuki Thajaja Purnama}

Dalam pasar modal yang efisien, pasar akan bereaksi secara cepat terhadap semua informasi yang relevan. Sehingga hal ini ditunjukan oleh perubahan harga saham melebihi kondisi normal, sehingga menimbulkan abnormal return. Jika suatu peristiwa yang terjadi mengandung informasi baik maka 
akan berdampak terhadap kenaikan abnormal return dan akan berdampak terhadap penurunan abnormal return jika informasi tersebut dianggap buruk.

\section{Trading Volume Activity Terhadap Vonis Basuki Thajaja Purnama}

Apabila peristiwa vonis yang diberikan Ahok mempunyai kandungan informasi yang menguntungkan maka akan berpengaruh terhadap saham yang terlihat dari perubahan trading volume activity. informasi yang akan dimiliki oleh investor akan tertransformasi dalam bentuk naik turunnya volume transaksi harian dan frekuensi transaksinya.

\section{Kerangka Pemikiran}

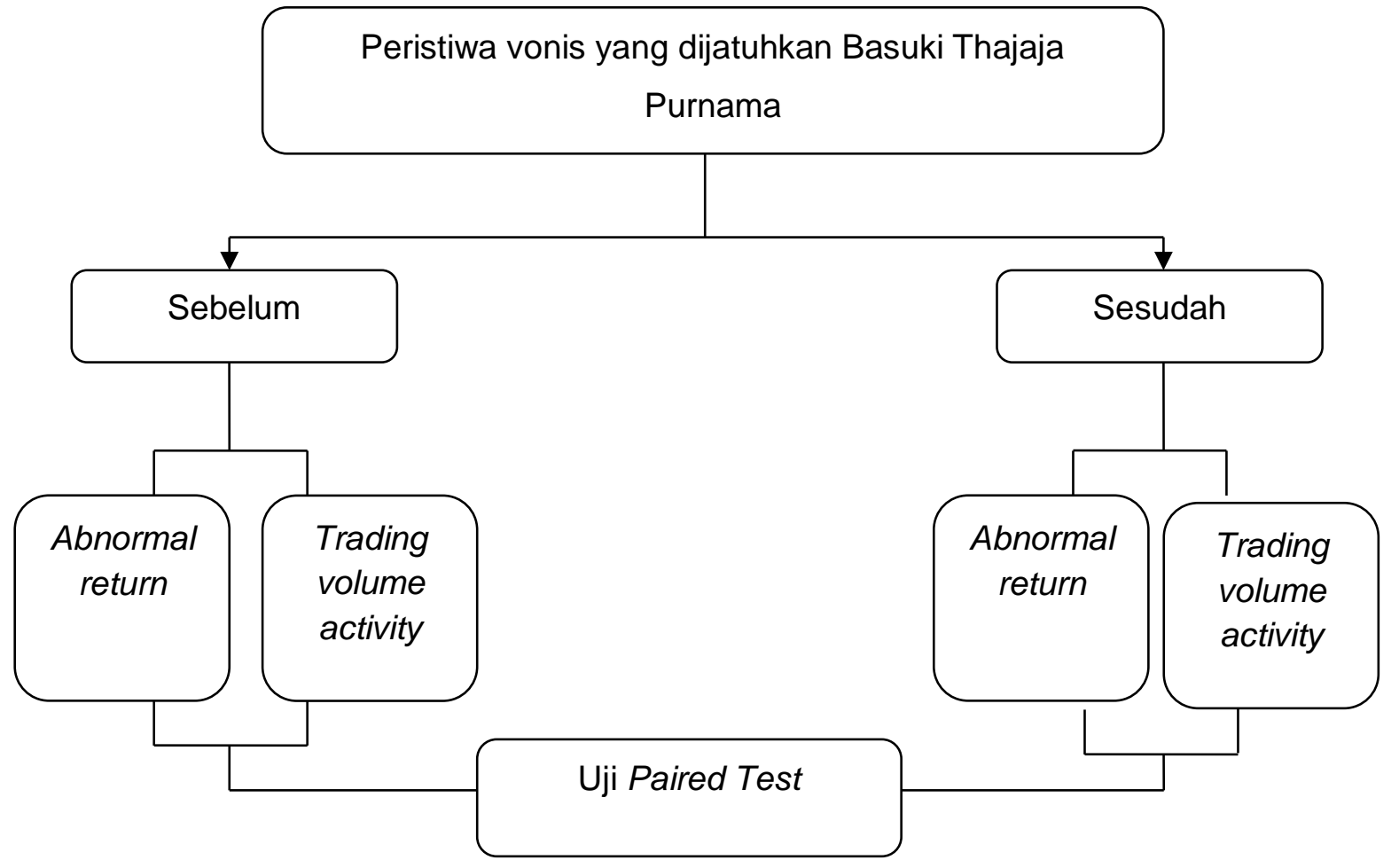

Gambar 1. Kerangka Pikir Penelitian

\section{METODOLOGI PENELITIAN}

Jenis penelitian yang digunakan dalam penelitian ini adalah event study. Studi peristiwa (event study) merupakan study yang mempelajari reaksi pasar terhadap suatu peristiwa yang informasinya dipublikasikan sebagai suatu pengumuman.Sementara itu, data yang digunakan di dalam melakukan penelitian ini adalah jenis data sekunder yang didapat dari website resmi Bursa Efek Indonesia (www.idx.co.id), website resmi harga saham perusahaan website www.yahoofinance.com. 


\section{Operasional Variabel}

1. Abnormal return adalah selisis antara tingkat keuntungan sebenarnya (acrual return) dengan tingkat keuntungan yang diharapkan (expected return). Pengukuran return menurut teori pasar dapat diformulasikan sebagai berikut (Jogiyanto, 2014:110):

$$
A R_{i t}=R_{i t}-\mathrm{E}\left[R_{i t}\right]
$$

Keterangan:

$A R_{\text {it }} \quad=$ return saham i pada periode ke $\mathrm{t}$

$R_{i t} \quad=$ harga penutupan saham $\mathrm{i}$ pada periode $\mathrm{t}$

$\mathrm{E}\left[R_{i t}\right]=$ harga penutupan saham i pada periode sebelumya

Adapun tahapan yang harus dilakukan untuk menghitung nilai abnormal return sebagai berikut:

1. Acrual return (Rit)

Return realisasian merupakan return yang telah terjadi (Jogiyanto 2015:263), return realisasian dihitungan menggunakan data historis. Adapun rumus yang digunakan untuk menghitung nilai acrual return sebagai berikut:

$$
R_{i t}=\frac{P_{t}-P_{t-1}}{P_{t-1}}
$$

Keterangan:

$R_{i t}=$ acrual return saham ke-i pada hari ke $\mathrm{t}$

$P_{t} \quad=$ harga saham ke-i pada hari ke-t

$P_{t-1}=$ harga saham ke-i pada hari sebelumnya (t-1)

2. Expected return $\left(\mathrm{E}\left[R_{i t}\right]\right)$

Return ekspektasian (expected return) adalah return yang diharapkan oleh investor dimasa yang akan datang (Jogiyanto, 2015:263). Model yang digunakan untuk menghitung nilai expected return dalam penelitian ini adalah single indeks market model (SIMM). Rumus yang digunakan unruk menghitung besarnya expected return sebagai berikut:

$$
\mathrm{E}\left[R_{i t}\right]=a_{i}+\beta_{i}\left[R_{m t}\right]
$$

Keterangan:

$\mathrm{E}\left[R_{i t}\right]=$ Expected return untuk saham pada hari ke-t

$a_{i}=$ nilai ekspektasian dari return saham yang independen terhadap return pasar 
$\beta_{i}=$ koefisien kemiringan (slope) yang merupakan beta dari saham ke-i

$\left[R_{m t}\right] \quad=$ return pasar (market return) dari indeks pasar selama periode peristiwa

3. Return pasar $\left[R_{m t}\right]$

Return pasar merupakan tingkat keuntungan yang ditunjukkan dalam bentuk indeks pasar.

Indeks pasar yang dapat digunakan adalah IHSG (indeks harga saham gabungan). Berikut rumus yang digunkan untuk menghitung nilai retun saham sebagai berikut:

$$
R_{m t}=\frac{I H S G_{t}-I H S G_{t-1}}{I H S G_{t-1}}
$$

Keterangan:

$$
\begin{aligned}
& R_{m t}=\text { return saham pada hari ke-t } \\
& I H S G_{t}=\text { IHSG pada hari ke-t } \\
& I H S G_{t-1}=\text { IHSG pada hari sebelumnya (t-1) }
\end{aligned}
$$

\section{Trading Volume Activity (TVA)}

TVA merupakan instrumen yang dapat digunkan untuk melihat reaksi pasar terhadap suatu informasi melalui parameter pergerakan aktivitas volume perdagangan saham di pasar modal (suryawijaya dan Faizal, 1998). Hasil perhitungan trading volume activity mencerminkan antara jumlah saham yang diperdagangkan dengan jumlah saham yang beredar dalam suatu periode tertentu. Jadi TVA diukur dengan formulasi sebagai berikut (Foster, 1986 dalam Husnan, 2006):

a. Menghitung TVA masing-masing saham selama periode penelitian yaitu:

$$
x=\frac{\sum \text { saham perusahaan } i \text { yang ditransaksikan pada hari ke } t}{\sum \text { saham perusahaan iyang beredar pada hari ke } t}
$$

\section{Populasi dan Sampel}

Populasi dalam penelitian ini adalah saham-saham yang terdaftar di indeks saham LQ-45 selama periode penelitian.Berikut merupakan kriteria untuk memilih sampel yang akan digunakan dalam penelitian yaitu:

1. Penelitian dilakukan terhadap perusahaan yang terdaftar pada indeks saham LQ-45 sejak periode Januari - Agustus 2017

2. Perusahaan tidak sedang melakukan corporate actions (pembagian deviden, stockplit dan right issue)atau menetapkan suatu kebijakan selama periode penelitian agar penelitian ini tidak terjadi confounding effect (efek bias) akibat adanya peristiwa lain yaitu adanya corporate actions 
3. Perusahaan yang dijadikan sampel yaitu perusahaan yang dinilai paling aktif melakukan transaksi di BEI selama periode penelitian

\section{Teknik Analisis Data}

Terdapat tiga pengujian statistic dalam penelitian ini:

\section{Deskriptif Statistik}

Deskriptif statistik digunakan untuk memberikan gambaran awal mengenai variabel yang digunkan dilihat dari rata-rata (mean) dan standar devisiasi dari setiap sampel yang digunakan.

\section{Uji Normalitas}

Uji normalitas dilakukan untuk menguji apakah data uji mempunyai distribusi normal atau tidak.

\section{Uji Hipotesis}

Uji hipotesis menggunakan Uji Paired Test yaitu digunakan untuk menjelaskan ada atau tidak nya perbedaan signifikan Abnormal return dan Volume Perdagangan (Trading Volume Activity) sebelum dan sesudah vonis yang diberikan Basuki Thajaja Purnama.

\section{HASIL DAN PEMBAHASAN \\ Hasil Uji Signifikansi Parsial/Uji T}

\section{Tabel Uji t}

\begin{tabular}{crrrr}
\hline \hline Variable & Coefficient & Std. Error & t-Statistic & Prob. \\
\hline \hline C & 0.123979 & 0.079653 & 1.556491 & 0.1240 \\
X1 & 0.409410 & 0.199880 & 2.048280 & 0.0442 \\
X2 & -0.000634 & 0.001599 & -0.396644 & 0.6928 \\
X3 & 0.208678 & 0.062438 & 3.342158 & 0.0013 \\
\hline \hline
\end{tabular}

Sumber: Hasil output eviews 10

Berdasarkan tabel di atas, maka dapat ditarik beberapa kesimpulan, yaitu:

1. Presentase penawaran saham berpengaruh terhadap tingkat underpricing pada perusahaan yang melakukan penawaran umum perdana (IPO) di Bursa Efek Indonesia.

2. Umur perusahaan berpengaruh terhadap tingkat underpricing pada perusahaan yang melakukan penawaran umum perdana (IPO) di Bursa Efek Indonesia.

3. Market timing berpengaruh terhadap tingkat underpricing pada perusahaan yang melakukan penawaran umum perdana (IPO) di Bursa Efek Indonesia.

\section{Hasil Uji Paired T-test Variabel Abnormal Return}

Paired Samples Test

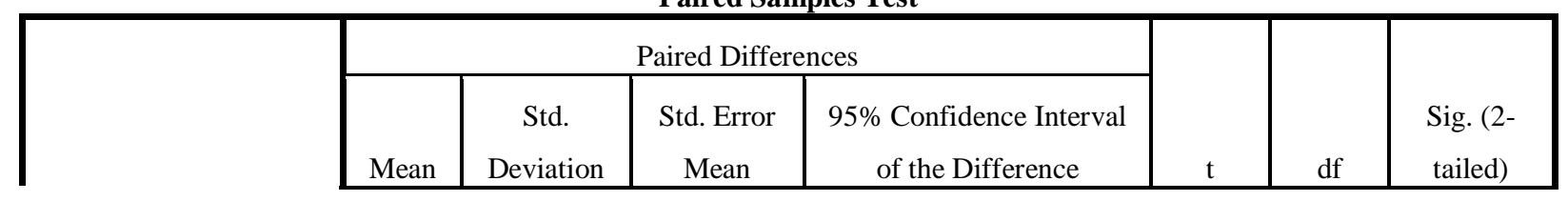




\begin{tabular}{|l|r|r|r|r|r|r|r|r|}
\hline & & & & Lower & Upper & & & \\
\hline Pair $\begin{array}{l}\text { sebelum }- \\
1\end{array}$ sesudah & 162,80 & 521,208 & 79,484 & 2,400 & 323,208 & 2,048 & 42 &, 047 \\
\hline
\end{tabular}

Berdasarkan Uji Hipotesis menggunakan Uji Paired Test pada tabel 4.5 diketahui bahwa statistik uji t yang dihasilkan sebesar 2,048 dengan probabilitas sebesar 0,047 yang artinya berarti probabilitas >level of significance dengan demikian dapat disimpulkan bahwa hipotesis diterima atau dinyatakan bahwa terdapat perbedaan yang signifikan pada Abnormal Return pada sebelum dan sesudah vonis Basuki Thajaja Purnama sehingga hipotesis diterima.

\section{Uji Wilxocon Rank Test}

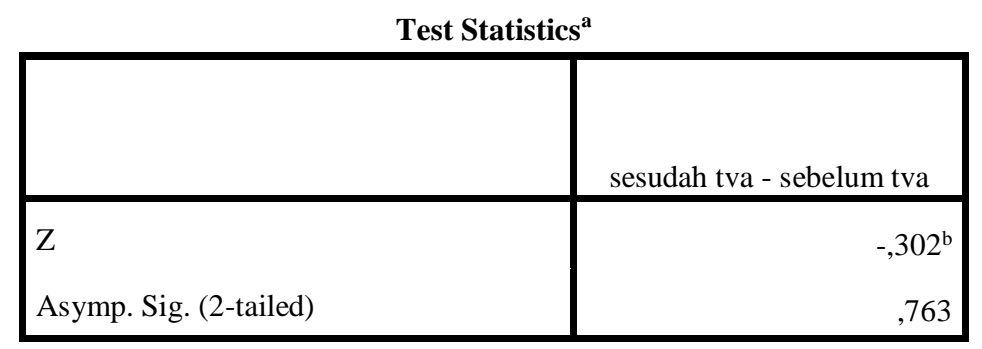

a. Wilcoxon Signed Ranks Test

Berdasarkan Uji Hipotesis Wilcoxon Rank Test diketahui bahwa Asymp.Sig. (2-Tailed) bernilai 0,763 yang artinya lebih besar dari >0,05 maka dapat disimpulkan hipotesis ditolak.

\section{PEMBAHASAN}

\section{Abnormal Return Terhadap Vonis Basuki Thajaja Purnama}

Hasil penelitian ini menunjukkan bahwa terbukti terdapat perbedaan Abnormal Return dari vonis yang dijatuhkan oleh Ahokdengan adanya signifikansi. Hal ini mengidentifikasikan bahwa vonis yang dijatuhkan oleh Ahok dianggap memiliki suatu kandungan informasi yang berpengaruh dan diserap oleh investor untuk mengambil keputusan di pasar modal. Abnormal Return yang tinggi memberikan keuntungan bagi para investor sedangkan Abnormal Return yang rendah memberikan kerugian atas pembelian saham atas keputusan berdasarkan informasi yang beredar. Dalam pengujian hipotesis Abnormal Return, secara statistik diperoleh kesimpulan bahwa nilai rata-rata Abnormal Return sebelum dan sesudah vonis Ahok adalah signifikan. Rata-rata Abnormal return pada sebelum vonis Ahok sebesar -85,48237117 dan setelah vonis Ahok sebesar -248,2862065

Dari segi teoritis yaitu ditinjau dari teori efisiensi pasar yang sangat berkaitan dengan persebaran informasi yang terdapat di pasar modal, serta seberapa cepat informasi tersebut diserap dan mendapatkan feedback dari investor karena informasi tersebut diperlukan dalam mengambil keputusan di pasar modal sehingga semakin cepat pasar modal melakukan reaksi terhadap informasi baru, maka semakin efisien pula pasar modal tersebut (Thandelilin, 2011). 
Hasil penelitian ini juga sesuai dengan penelitian yang dilakukan oleh Liwe, Tommy dan Marais (2018) serta Lia dan Endi (2012) yang menyatakan bahwa terdapat perbedaan Abnormal Return terhadap suatu peristiwa.Namun tidak mendukung penelitian Luhur (2010), Dewi dan Putra (2013) dan Dewi, Amin dan Mawardi (2018).

\section{Volume Perdagangan (Trading Volume Activity) sebelum dan sesudah vonis yang diberikan} Ahok

Hasil pengujian hipotesis kedua membuktikan bahwa secara statistik tidak terdapat perbedaan yang signifikan antara TVA sebelum dan sesudah vonis yang diberikan Ahok tidak terbukti. Berdasarkan rata-rata TVA sebelum vonis Ahok sebesar 0,01617 dan sesudah vonis yang diberikan Ahok sebesar 0,011217.

Informasi yang berupa vonis Ahok dapat menyebabkan permintaan dan penawaran meningkat atau menurun terhadap saham maka akan memberikan naik turunnya (fluktuasi) volume perdagangan saham sehingga dalam hipotesis ini tidak terbukti. Hasil penelitian justru membuktikan bahwa vonis yang diberikan Ahok tidak terdapat perbedaan TVA sebelum dan sesudah vonis Ahok. Tidak adanya reaksi pasar yang signifikan sebelum dan sesudah vonis ahok mengidentifikasikan bahwa investor belum mengantisipasi secara cepat informasi yang diterima dipasar modal sehingga tidak terjadi perbedaan volume yang signifikan sebelum dan sesudah vonis yang diberikan Ahok.

Hasil penelitian ini juga mendukung penelitian terdahulu yang dilakukan oleh terhadap suatu peristiwa.Namun tidak mendukung penelitian Luhur (2010), Dewi dan Putra (2013) dan Dewi, Amin dan Mawardi (2018) bahwa tidak terdapat perbedaan volume perdagangan (Trading Volume Activity) pada peristiwa. Namun tidak mendukung penelitian yang dilakukan oleh Liwe, Tommy dan Marais (2018) serta Lia dan Endi (2012).

\section{Kesimpulan}

Berdasarkan analisis yang dilakukan terhadap hipotesis maka dapat diambil kesimpulan sebagai berikut:

1. Variabel Abnormal Return menunjukkan terdapat perbedaan yang signifikan. Hal ini mengartikan bahwa vonis yang diberikan Ahok dianggap sebagai suatu informasi oleh investor untuk mengambil keputusan di pasar modal

2. Variabel Volume Perdagangan (Trading Volume Activity) secara stratistik tidak terjadi peningkatan volume perdagangan. Hal ini menunjukan bahwa tidak terdapat perbedaan yang signifikan antara sebelum dan sesudah vonis yang diberikan Ahok.

Berdasarkan kesimpulan di atas maka terdapat beberapa saran agar peneliti selanjutnya dengan menggunakan metode event study menjadi lebih baik: 
1. Diharapkan untuk sampel yang digunakan peneliti selanjutnya menggunakan sampel lain seperti menggunakan indeks kompas 100, sub sektor seperti manufaktur, perbankan dan lain-lain agar hasilnya beragam.

2. Untuk menggunakan metode event study diharapkan menggunakan metode Capital Asset Pricing Model (CAPM) agar hasil penelitian dapat bervariasi dan semakin baik.

3. Untuk pembaca umumnya dan khusus nya untuk investor maupun calon investor agar lebih berhati-hati terhadap suatu informasi yang terjadi sehingga dalam mengambil keputusan di pasar modal sehingga biasanya pasar akan berekasi sementara untuk mencapai keseimbangan baru atas informasi yang tersedia. Lebih baik menganalisis ulang secara fundamental dan teknikal agar meminimalisir resiko akibat suatu peristiwa yang terjadi.

\section{DAFTAR PUSTAKA}

Dewi, Amin \& Mawardi. 2018. Reaksi Investor Dalam Pasar Modal Terhadap Peristiwa Aksi Bela Islam 4 November 2016 Di Jakarta. Fakultas Ekonomi dan Bisnis Universitas Islam Malang, Volume. 07, Nomor. 07 Agustus 2018

Hendrawijaya, Michael. 2009. Analisis Perbandingan harga Saham, Volume Perdagangan Saham dan Abnormal Return Saham Sebelum Dan Sesudah Pemecah Saham. Tesis. Universitas Diponegoro

Https://www.idntimes.com/news/indonesia/gregorius-pranandito/perjalanan-kasus-ahok-bermuladari-pidato-hingga-akhirnya-di-penjara/full diakses pada 19 April 2019

Https://www.idx.co.id

Islami, Lia Nur dan Sarwoko, Endi. 2012. Reaksi Pasar Modal Indonesia Terhadap Pergantian Menteri Keuangan (event study saham yang trdaftar di BEI). Fakultas Ekonomi Universitas Kanjuruhan Malang. Volume. 8, Nomor. 1 Februari 2012

Kosasi, Aldi. 2017. Analisis Pengaruh Book To Market Equality, Firm Size, Market Value Added, Momentum dan Trading Volume Activity Terhadap Return Saham. Skripsi. Fakultas Ekonomi dan BisnisUniversitas Dipoenegoro Semarang

Luhur, Suryo. 2010. Reaksi Pasar Modal Indonesia Seputar Pemilihan Umum 8 Juli 2009 Pada Saham LQ 45. Jurnal Keuangan dan Perbankan, Volume. 14, Nomor. 2 Mei 2010, hal 249-262

Manik, Sondakh \& Rondonuwu. 2017. Analisis Reaksi Harga Saham Sebelum Dan Sesudah Tax Amnesty Periode Pertama (Studi Kasus Saham Sektor Properti Yang Tercatat Di Bursa Efek Indonesia). Volume. 5, Nomor. 2 Juni 201, Hal 762-772

Mansur \& Jumaili. 2014. Reaksi Pasar Modal Terhadap Peristiwa Pemilihan Umum Tahun 2014 Pada Perusahaan terdaftar DI Bursa Efek Indonesia. Volume. 6, Nomor. 2, Hal. 59-68

Mansur, Fitrini \& Jumailli, Salman. 2014. Reaksi Pasar Modal Terhadap Pemilihan Umum Tahun 2014 Pada Perusahaan Terdaftar di Bursa Efek Indonesia. Fakultas Ekonomi Universitas Jambi. Volume 16, Nomor 2, Hal.58-68

Naibaho. 2018. Pengaruh Kasus Ahok Terhadap Pergerakan Harga Saham Nasional (Studi Kasus Pada Indeks Saham LQ-45 Yang Terdaftar Di Bursa Efek Indonesia. Skripsi. Fakultas Ekonomi dan Bisnis Universitas Diponegoro 
Prameswari \& Wirakusuma. 2018. Analisis Reaksi Pasar Modal Pada Peristiwa Pemilihan Gubernur DKI Jakarta Tahun 2017. Jurnal Akuntansi Universitas Udayana, Volume. 22, Nomor. 2 Februari 2018.

Sinarwati, Ni Kadek \& Nyoman A.S.D. 2015. Reaksi Pasar Modal Indonesia Terhadap Peristiwa Politik (Event Study pada peritiwa pelantikan Joko Widodo Sebagai Presiden Republik Indonesia ke-7. Universitas Pendidikan Ganesha Singaraja

Tandelilin, Eduardus. 2010. Portofolio dan Investasi, edisi 1. Yogyakarta: Kanisius

Trisnawati, Fenny. 2011. Pengaruh Peristiwa Politik Terhadap Perubahan Harga Saham. Pekbis Jurnal, Volume. 3, Nomor. 3, November 2011: 528-535.

Yuniati, Tri. 2017. Analisis abnormal return dan trading volume activity saham LQ-45 pada seputar peristiwa pengumuman kebijakan pengampunan pajak (tax amnesty). Skripsi. Universitas Lampung.

Zaqi, Muhammad. 2006. Reaksi Pasar Modal Indonesia Terhadap Peristiwa-peristiwa Ekonomi Dan Peristiwa-peristiwa Sosial Politik Dalam Negeri. Tesis. Universitas Diponegoro. 